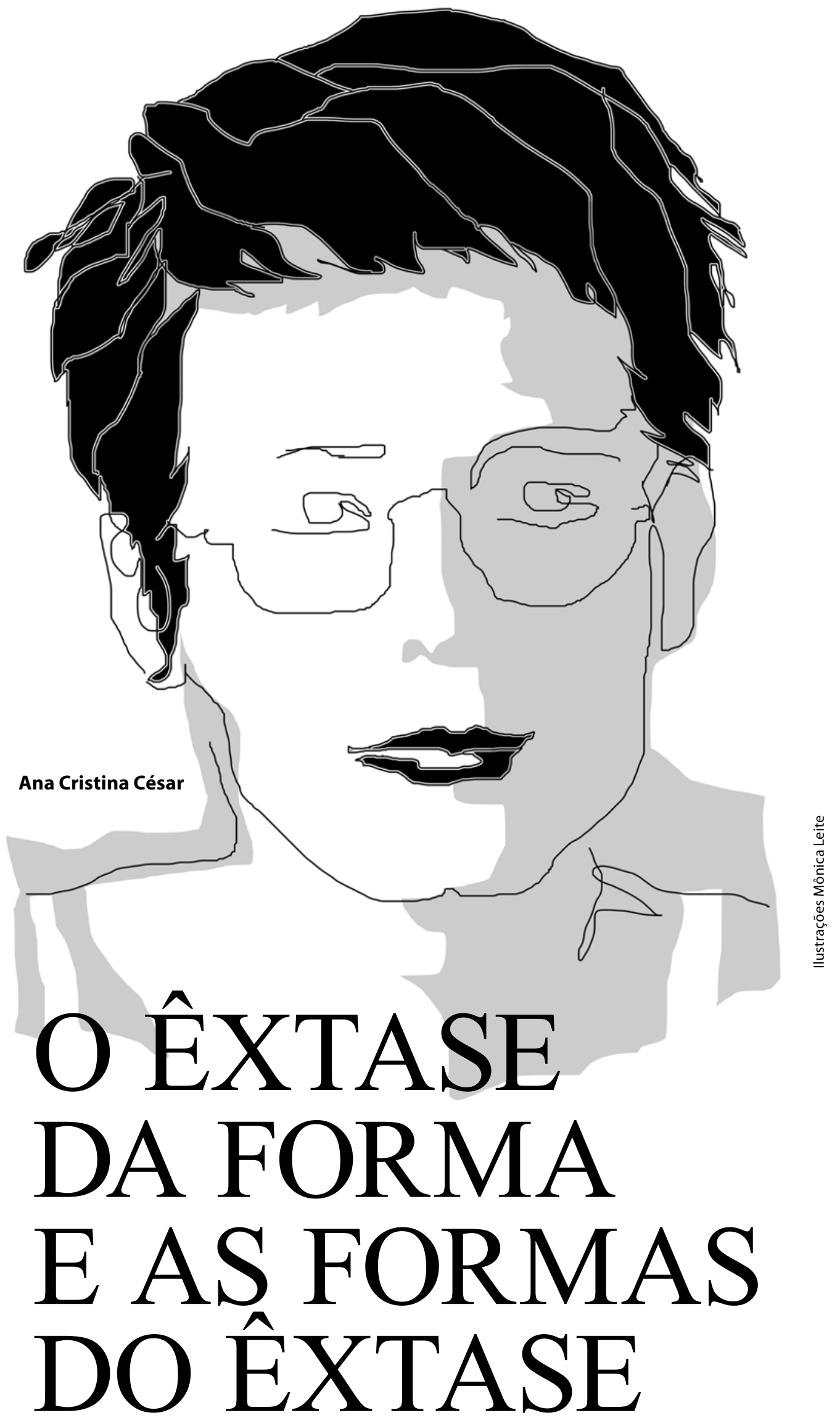

Aguinaldo José Gonçalves 


\section{ABRI CURIOSA}

OCÉU.

ASSIM, AFASTANDO DE LEVE AS CORTINAS.

\section{EU QUERIA RIR, CHORAR, \\ OU PELO MENOS SORRIR \\ COM A MESMA LEVEZA COM QUE}

OS ARES ME BEIJAVAM.

\section{EU QUERIA ENTRAR, \\ CORAÇ̃̃O ANTE CORAÇÃO, \\ INTEIRIÇA, \\ OU PELO MENOS MOVER-ME UM POUCO, COM AQUELA PARCIMÔNIA QUE CARACTERIZAVA AS AGITAÇÕES ME CHAMANDO.}

\section{EU QUERIA ATÉ MESMO}

\section{SABER VER,}

E NUM MOVIMENTO REDONDO

COMO AS ONDAS

QUE ME CIRCUNDAVAM, INVISIVEIS,

ABRAÇAR COM AS RETINAS

CADA PEDACINHO DE MATÉRIA VIVA.

EU QUERIA
(SÓ)
PERCEBER O INVISLUMBRÁVEL
NO LEVIÍSSIMO QUE SOBREVOAVA.

EU QUERIA
APANHAR UMA BRAÇADA
DO INFINITO EM LUZ QUE A MIM SE MISTURAVA.

\section{EU QUERIA}

CAPTAR 0 IMPERCEBIDO

NOS MOMENTOS MÍNIMOS DO ESPAÇO

NU E CHEIO.

\section{EU QUERIA}

AO MENOS MANTER DESCERRADAS AS CORTINAS

NA IMPOSSIBILIDADE DE TANGË-LAS.

EU NÃO SABIA

QUE VIRAR PELO AVESSO

ERA UMA EXPERIENNCIA MORTAL

\section{(ANA CRISTINA CÉSAR)}

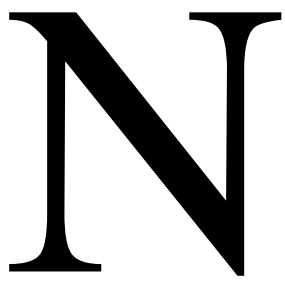

o exercício de vivência crítica, ocorrem às vezes certos fenômenos que parecem justificar por si mesmos todo o empenho que despendemos no trabalho, muitas vezes difícil, de perquirição da forma e dos meandros divagantes que tendem a construir o discurso literário. Na verdade, por mais que não queiramos assumir, vivemos em busca de invariantes, de determinadas convergências que possam, se não iluminar totalmente, ao menos mostrar determinados clarões que delineiem formas ocultas nas veredas da linguagem literária. No presente exercício crítico, gostaria de apontar um desses clarões que resvala o universo de quatro grandes escritoras, munidas de um movimento de formas que se criaram, evolvendo-as, cada uma a seu tempo, e fascinando-as, com intensidades similares. Refiro-me às escritoras Katherine Mansfield, Virgínia Woolf, Clarice Lispector e Ana Cristina César. Realizaram trabalhos excepcionais e foram modelares no que diz respeito a notações biográficas singulares. As quatro se uniram por meio do feito literário, por meio do grau de expressão e de modulação de suas obras. Cada uma, portando estilo singular, remete-se à outra por uma fina nódoa de estranhamento, que acaba por enriquecer o nosso olhar para o objeto literário e obscurecer, em tom azul-marinho, esse mesmo olhar para as camadas imediatas da realidade. $\mathrm{O}$ que houve, e isso não é comum, foi uma convergência do gosto estético e da percepção para um mesmo
AGUINALDO JOSÉ GONÇALVES é poeta, ensaísta, crítico de arte e professor de Literatura Comparada da Unesp. É autor de, entre outros, signos(em)cena (Ateliê). 
ponto; três delas sentiram-se profundamente atraídas pelo estilo de uma quarta escritora, que lhes serviu como a fonte de obsessões impressivas, que na verdade dialogavam com suas distintas tendências estilísticas. Em literatura, fala-se costumeiramente de influências, de movimentos intertextuais, de outros modos de apoderações de estilos. Não será disso que falaremos aqui. Não é o procedimento natural na história das formas que abordaremos. A impressão que se tem é que o estilo da escritora Katherine Mansfield, nascida em 1888 e morta em 1923, com apenas 31 anos de idade, parecia estar girando em órbita absoluta à espera de uma brecha que possibilitasse a entrada de suas parceiras de percepção e por esse caminho fossem ocorrendo outras bolhas de expressão, detidas, contidas e expressivas, realizadas a suas maneiras e a seu tempo. Sem que pertencesse a algum grupo literário específico, a não ser ao modernismo inglês, essa escritora, que em princípio tem dúvidas sobre sua vontade mais profícua de escrever, inicia esse exercício, refratando no estilo como quem respira, e refratando na vida de uma maneira extremamente natural. Em pleno início do século $\mathrm{XX}$, com todos os movimentos sociais contrários a uma libertação dos valores morais, Mansfield se insurge pungente e "bêbada" nas esferas sociais. Ela se impõe ícone de uma visão que por nada a faz recuar, e inicia uma produção das mais originais de todos os tempos.

Mas não é bem desse procedimento natural que estamos falando. Indo direto ao assunto que nos põe a pena na mão, quero discutir um desses movimentos estéticos de relevância, nada comuns na história das formas da evolução literária. Trata-se do meandro divagante que se criou entre essas escritoras excepcionais, sendo que três delas, cada uma no seu ritmo e na sua grandeza, unidas e munidas pelo estilo e pela originalidade, perceberam a primeira delas, que, sozinha, se insurgia na literatura indo fundo no seu modo de narrar. Independente da nomenclatura que possa ser conferida ao fenômeno, o que se releva nele é a discussão da essência da literatura no seu alto padrão de eficácia.

Uma vez que nosso interesse reside na existência do autor e nas complexas relações que se estabelecem entre sua vida e seu trabalho de transmutação do mundo empírico para o mundo da palavra, vamos aproximar a câmera numa espécie de meandro divagante literário, de ocorrência rara na história literária. Evidentemente não são nada raras as relações de influências de um autor para outro ou de uma obra para outra. Menos comuns, mas que também devemos assinalar como preciosa ocorrência, são os casos em que a obra posterior é precursora da obra anterior. Realizada sob a luz de outra não tão reconhecida ou valorizada pela crítica, a obra atual vai reconduzir à verdadeira valorização da anterior.

É com todo o cuidado, que passamos aqui a um trabalho de aproximação crítica entre as quatro escritoras acima nomeadas, cada uma estrela maior de sua constelação e como um fenômeno sideral, suas luzes se tocaram e criaram um resultado bastante singular. Alguns passos dessa aproximação são bastante fáceis para se compreender e outros, nem tanto.

Kathleen Mansfield Beauchamp nasceu em uma família socialmente proeminente em Wellington, Nova Zelândia. Filha de um banqueiro e nascida em família colonial de classe média, Mansfield teve uma infância solitária e alienada. Suas primeiras histórias publicadas apareceram no High School Reporter e na revista do colégio para garotas de Wellington, em 1898 e 1899. Mudou-se para Londres em 1902, onde frequentou o Queen's College. Violoncelista de talento, inicialmente não se sentiu atraída pela literatura e, após concluir sua educação na Inglaterra, voltou para a Nova Zelândia em 1906. Foi somente depois desse retorno que Kathleen Beauchamp começou a escrever contos. Cansada do estilo de vida provinciano da Nova Zelândia da época, Beauchamp retornou a Londres dois anos mais tarde, em 1908, e passou a impor um sistema de vida bastante ousado e desregrado para a época. Vivenciando uma experiência boêmia, optou pela bissexualidade e por atitudes heterossexuais que fugiam à considerada conformidade dos bons costu- 
mes. Conheceu, casou-se e separou-se de seu primeiro marido, George Bowden, tudo em período de três semanas. Katherine (esse foi o nome que assumiu como escritora), nessa mesma época, engravidou de um amigo da família da Nova Zelândia, Garnet Trowell, um violonista profissional, e sua mãe a mandou para a Baviera. Mansfield perdeu seu bebê em 1909. No retorno à Inglaterra, seu trabalho chamou a atenção de várias editoras quando da publicação de sua primeira coleção de contos, In a German Pension (Numa Pensão Alemã), em 1911. Contraiu gonorreia por volta dessa época, um evento que a faria sofrer com dores de artrite pelo resto de sua curta vida, bem como enxergar-se como uma mulher "suja". Iniciou-se assim a brilhante e sempre surpreendente carreira de Katherine Mansfield, que respondia com a linguagem sempre dribladora e mágica às exigências de editores muitas vezes contraditórios. Depois de não ter a receptividade que esperava por obras em que investiu seu talento, enviou uma trama leve para uma revista moderna chamada Rhythm, que foi rejeitada pelo editor John Middleton Murry, que pediu algo mais sombrio. Mansfield respondeu com "The Woman at the Store" ("A Mulher na Loja"), uma história de assassinato e doença mental que Murry chamou de "de longe a melhor história mandada à Rhythm". Em 1912 Murry visitou Mansfield no seu apartamento, onde ela lhe serviu chá em tigelas porque não possuía xícaras. Visitantes frequentemente a encontravam vestida num quimono. Mansfield, atraída por ele, o convidou a se mudar para o quarto de hóspedes logo após sua publicação, e logo em seguida eles começaram seu relacionamento conturbado, que incluiu casamento em 1918. Eles se mudaram diversas vezes e frequentemente viveram separados.

Aparentemente ambos não acreditavam em uniões estáveis, e Mansfield pode ter se arrependido de seu estilo de casamento. Sua amiga próxima, Ida Baker, frequentemente cuidava dela quando estavam separados. A grande escritora alterou seu ritmo de trabalho depois da morte do irmão como comba- tente da Primeira Guerra Mundial. Passou por estados de depressão e sua obra se voltou para certos temas mais nostálgicos incluindo memórias da sua infância na Nova Zelândia. Foi nessa época que Mansfield passou a ter amizades profissionais e manter diálogos literários com alguns escritores proeminentes, como D. H. Lawrence e Virgínia Woolf. No caso de Woolf, Katherine teve algumas conversas em função de seu trabalho narrativo, que passaram a ser publicadas pela editora criada por Leonard Woolf e a autora de $\mathrm{Or}$ lando e Rumo ao Farol. A fleumática e arguta escritora, depois de ter criticado Mansfield por seus modos sociais ou pelo seu mau gosto para se vestir, reconheceu após sua morte a sua admiração pela "rebelde" contista e chegou a reconhecer, em Katherine, "a única escrita que eu invejei". É curioso termos de salientar que foi no período em que mais se debilitava sua saúde (1917-18), com crises de depressão e contraindo tuberculose, tendo hemorragias seriíssimas, que melhores trabalhos escreveu ou trabalhos que a deixariam mais conhecida. "Miss Brill", uma história sobre uma mulher frágil vivendo uma vida efêmera de observação e prazeres simples em Paris, estabeleceu Mansfield como um dos escritores modernistas preeminentes, quando da sua publicação em 1920 na coleção Bliss. A história título dessa coleção Bliss (Felicidade), que envolvia uma personagem semelhante enfrentando a infidelidade de seu marido, também recebeu crítica favorável. Ela seguiu com a coleção igualmente louvada, The Garden Party, publicada em 1922.

Mansfield passou seus últimos anos buscando curas cada vez mais não ortodoxas para sua tuberculose. Em fevereiro de 1922, ela consultou o médico russo Ivan Manoukhin. Seu tratamento "revolucionário", que consistia em bombardear seu baço com raios $\mathrm{X}$, fez com que Mansfield desenvolvesse calores e insensibilidade nas pernas. Nos últimos anos de sua vida ela passou a sentir que sua atitude perante a vida havia sido exageradamente rebelde e procurou renovar sua vida espiritual. Em outubro de 1922, Mansfield mudou-se para o Instituto para o Desenvol- 
vimento Harmonioso do Homem, de Georges Gurdjieff, em Fontainebleau, França, onde esteve sob os cuidados de Olgivanna Lazovitch Hinzenburg (posteriormente, Sra. Frank Lloyd Wright). Mansfield sofreu uma hemorragia pulmonar fatal em janeiro de 1923, após subir uma escada correndo para mostrar a Murry quão bem estava. Foi enterrada em um cemitério no distrito de Fontainebleau, na cidade de Avon. Mansfield provou ser uma escritora prolífica nos últimos anos de sua vida, e uma boa parte de sua prosa e poesia não foi publicada até depois de sua morte. Murry se predispôs a editar e publicar seus trabalhos. Seus esforços resultaram em dois volumes adicionais de contos em 1923 (The Dove's Nest) e, em 1924, Something Childish, bem como seus Poems, The Aloe, uma coleção de escritos críticos (Novels and Novelists) e um número de edições de trabalhos previamente não publicados de suas cartas e diários. Dentro de sua grande produção, novelas, coletâneas de contos, poemas, textos críticos e outros gêneros, enumerarei alguns contos por terem identidades especiais na sua obra.

O que nos moveu criticamente para escrever este breve ensaio foi o fenômeno estético no seu sentido estrito. A relevância de Katherine Mansfield foi ter descoberto alguns procedimentos narrativos que fizeram a diferença na composição literária em termos de construção do estranho, do inusitado, que toma o leitor automatizado com as leituras tradicionais realistas do período precedente e o lança para a percepção do desequilíbrio da realidade, de seu caráter singular. Curioso é que a escritora parece, na escritura, estabelecer uma relação de homologia com sua vida de refrações e de natural coragem de ser. Os temas foram os mais cotidianos, mas a abordagem estilística, a mais sofisticada do ponto de vista literário. Mansfield parece trazer em si o universo da surpresa narrativa, originalidade na trama munida por pequenos sobressaltos que nunca o leitor vai deduzir ou inferir por procedimentos previsíveis. Sendo assim, seus contos trazem uma forma inquestionável de tratar a realidade por meio de um olhar de viés e extremamente crítico

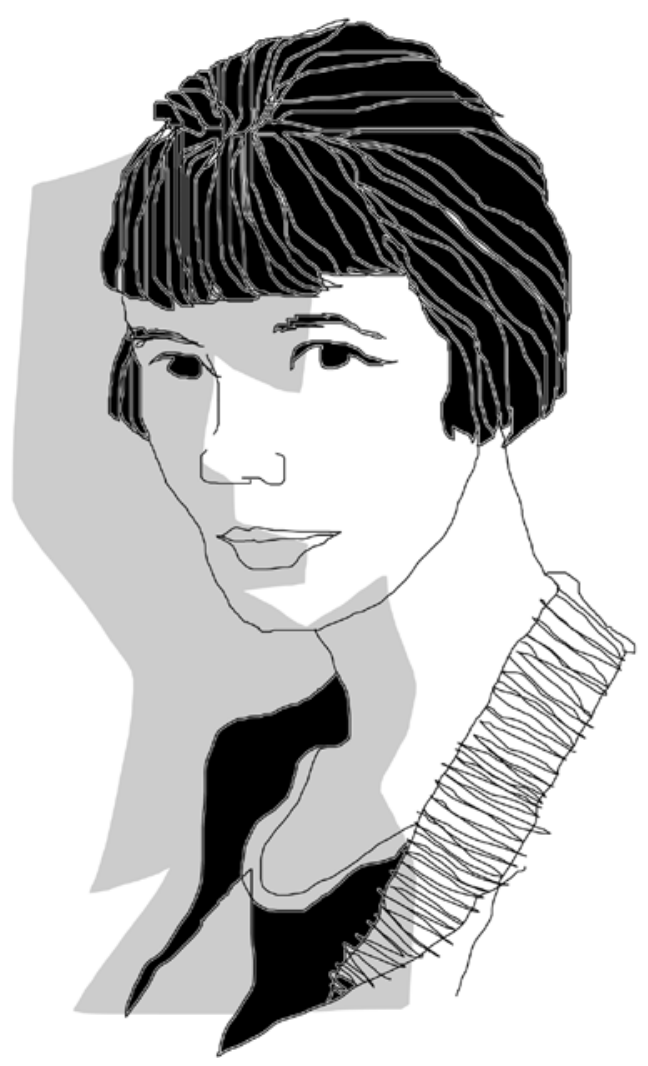

Katherine Mansfield

sem, de maneira alguma, se valer do lugar comum. Ela parte quase sempre do conhecido, do convencional ou até mesmo do prosaico para nos conduzir ao crespo das coisas, ao avesso do tecido volátil da linguagem. Havia lido alguns contos de K. Mansfield no original inglês e há pouco tempo li seus contos (do original Twelve Stories) na tradução de Carlos Eugênio Marcondes de Moura e Alexandre Barbosa de Souza. Refiro-me aos doze contos publicados pela Cosac Naif em 2005. Conforme evoluímos na leitura desses textos, parece ocorrer um processo de atração involuntária para o universo de cada conto, de cada ambiência ficcional, em cada desenvolvimento de trama, todos eles tendo como invariante uma linguagem dotada de um estilo marcado pela clareza e pelo drible inteligente na apresentação do surpreendente e da serena ironia. Os contos, todos eles, são extraordinários. A mente criadora da Katherine não permite que haja um desvio qualquer no procedimento modulador de cada composição. $\mathrm{O}$ crítico é tomado por um desejo de comentar cada um dos textos perdendo o senso comparativista que elege este ou aquele para trazer à baila dos estudos. Logo 
que li os Doze Contos, um parecia querer ganhar terreno nas minhas predileções críticas. Refiro-me ao último conto do livro, denominado "A Mosca". O conto tomou-me por uma surpreendende forma de armar a trama e apontar artisticamente para temas como crueldade, piedade e frívolo retrato da condição humana. Entretanto, "A Mosca", sendo o último, fez-me voltar ao primeiro, denominado "Alemães Comendo", em que certo hiper-realismo atravessa a ambiência familiar e nos arremessa à realidade da Primeira Guerra Mundial, brilhantemente alegorizada pela trivial conversa à mesa entre Herr Rat, a narradora, e Fräulein Stiegelauer. A partir do momento em que compreendemos as intenções das palavras e dos semissímbolos do conto, somos obrigados a voltar para buscar melhor compreensão. E, assim, vão desfilando os outros contos até mais complexos na estrutura e no grau de estranhamento que provocam, como é o caso de "Je ne Parle pas Français" ou "Uma Viagem Indiscreta", um dos mais intrigantes de todo o livro.

Foi a leitura desses contos de Katherine Mansfield e o consequente atordoamento provocado por ela que me levaram a buscar mais e, nessa busca, chegaria ao ninho da serpente. Chegaria aos contos que consolidariam a sua grandeza e a fonte para a germinação de motivação de outros criadores de excelência. Refiro-me às obras The Garden Park e, especialmente, Bliss. A tradução do conto "Bliss" por Érico Veríssimo, com o título "Felicidade" (1940), recobre timidamente o verdadeiro espírito da genial narrativa. Entretanto, foi a genuína poetisa da pós-modernidade, Ana Cristina César (195283), pertencente à chamada poesia marginal da década de 70, que atingiu o cerne desse conto para a língua portuguesa por volta de 1981, traduzindo-o por "Êxtase", acompanhado de excelentes notas com comentários críticos. Essa tradução foi resultado de um trabalho acadêmico, matizado pelo olhar da poetisa embevecido pelo universo de Katherine. Bliss foi publicado pela primeira vez em 1920, e, em 1922, The Garden Party, a obra que veio garantir-lhe a reputação. Já estava muito ruim, a doença a foi destruindo firme e inteiramente, primeiro a já citada e não diagnosticada e não tratada gonorreia e, depois, a tuberculose. Foi assim doente que percorreu várias partes da Europa, "errando" entre a literatura e um certo misticismo. Continuou escrevendo seus contos, seu famoso diário e suas não menos famosas cartas. Em todos os escritos os críticos encontram uma profundeza enorme de observação; uma singela expressão do que há de intraduzível na alma humana e uma complexa feminilidade surpreendendo as estranhas raízes que a prendiam à vida. $\mathrm{O}$ que se deve explicitar é que, com a sua magnífica tradução de "Bliss", Ana Cristina César não foi apenas uma tradutora de Katherine Mansfield, mas ela teve o violento (no sentido extático) gesto de apresentar a verdadeira Katherine de corpo inteiro ao Brasil e, salvo as proporções, é como se fora Baudelaire apresentando Poe à França.

Lendo a obra poética de Cristina César e atentando para seu estilo quase nunca fácil, pelo contrário, composto de uma acidez e de uma irreverência ímpares, não fica difícil compreender os gestos mentais de Katherine rondando o seu estilo meio século depois da morte da escritora nascida na Nova Zelândia. Como analisa Katiuce Lopes Justino (em pesquisa de doutorado em andamento na Universidade Estadual Paulista), especialista na poetisa brasileira, a poesia de Ana Cristina César caracteriza-se por ser aparentemente confessional, mas o tom de intimidade não nos deve enganar, pois é apenas um lance de sedução estética. Baseando-se nas considerações críticas de Armando Freitas Filho, a pesquisadora prossegue dizendo que a correspondência teve bastante influência sobre a dicção poética de Cristina César. Ela cria um verdadeiro jogo de linguagem: textos curtos, poemas fragmentados, cartas, páginas de diário. A poesia torna-se, dessa forma, uma inquietante reflexão sobre o próprio fazer literário. Nessa linha de abordagem, há de se assinalar, na invenção poética de Ana Cristina César, a utilização de uma mescla de discursos, estabelecendo a tensão entre os limites dos gêneros que estão a todo 
tempo se tangenciando na sua poesia: a carta, o diário, a publicidade, etc. recaem numa bricolagem poética, produzindo efeito provocativo, exageradamente dramático e fatalmente irônico em relação a si mesma. Ana Cristina enfatiza aspectos cênicos e constrói cenário e texto nos quais pode estrear a paródia da mulher escritora, perdida entre as conquistas do feminismo e da contracultura, por um lado, e, por outro, presa ao autobiografismo do diário íntimo. Num primeiro momento, não sentimos a relação entre a poetisa brasileira dos anos 70 e a contista Katherine Mansfield. Entretanto, indo mais fundo nos seus poemas e analisando o "olhar de viés" que lançou ao mundo e a forma como sua linguagem capturou ou expressou esse olhar, compreendemos que a relação não apenas era intensa como se poderia também compreender a poetisa como pertencendo à mesma linhagem da de Katherine. Seus poemas revelam também a intensa atração pelo estranho, manifestado pelo insólito e pelo crespo da realidade posta em forma de linguagem. Como aponta a crítica mais especializada, sua poesia deu ênfase à experiência existencial num momento especialmente difícil da história e da política brasileiras; volta à primeira pessoa, à escrita da paixão e do medo como caminho eficaz no sentido de romper o silêncio e a perplexidade que tomaram de assalto a produção cultural no início da década; o sentido de asfixia, experimentado no cotidiano, mas trabalhado com humor; valorização do coloquialismo; culto do instante, eixo fundamental da nova poesia e do binômio arte e vida. Esse binômio era a consolidação de uma visão de mundo que valorizava o aqui e o agora: a ideia do presente eliminando a ideia de futuro. A coerência dentro da irreverência dessa poesia seria sua marca registrada. Em momento algum houve um recuo nos procedimentos (des)construtivos utilizados pela poetisa brasileira. Na sua curta vida seu estilo se fixou e se solidificou, tornando-a cada vez mais uma das mais convincentes representantes de sua geração. Poder-se-ia dizer que não houve nada nem ninguém que conseguisse segurar
Katherine Mansfield e "educar" seus passos rumo ao certeiro, ao ponderável, durante sua curta e ziguezagueante vida. Não houve nada nem ninguém que conseguisse segurar Ana Cristina César e "educar" seus passos rumo ao certeiro, ao ponderável, durante sua curta e ziguezagueante vida.

É chegado o momento de assinalar o primeiro dueto. As suas ações refratárias tiveram repercussões nos meios em que viveram, e refletiram de modo frutífero para a evolução do sistema literário por meio de seus talentos e de suas coragens de colocar isso a nu, mesmo que em prejuízo de suas próprias vidas. Em certos momentos em que penso nessas duas escritoras e/ou nessas duas vidas, tenho a sensação de Arthur Rimbaud passando ao longe acenando, navegando no seu bateau ivre. A intensidade de sua produção literária dominou todos os percalços, todos os sofrimentos e todas as intemperanças de temperamento e sua voluptuosidade vital. Nesse mundo vivido e experimentado, essa figura genial da literatura de língua inglesa revelou uma arguta percepção da realidade aliada a um modo de escrever que conseguia flagrar as reentrâncias e saliências dessa realidade, alterando-a, metamorfoseando-a e devolvendo-a para o mundo como meio ou como princípio para desestabilizar todas as coisas, tirá-las fora do lugar e criar um novo espaço todo novo e, logicamente, estranho, genuinamente estranho, no sentido estabelecido por Victor Chklovski e acordado por todos os que vieram depois dele. $\mathrm{E}$ foi esse olhar de viés, que revelava com intensidade deslocamentos e procedimentos de estilo, que foi percebido primeiramente por sua contemporânea Virgínia Woolf e depois por Clarice Lispector. A autora de Rumo ao Farol e Orlando, que ofereceu certa resistência a Katherine, reconheceu, após sua morte, ter sentido "inveja de escrita" diante do estilo da autora de Bliss.

Foi por meio do contemporâneo, dessa relação entre a poetisa brasileira e o texto de Katherine, que voltei ao "tempo de Mansfield" nas duas primeiras décadas do século $\mathrm{XX}$ e descobri o outro e forte fio da teia, ou 
o outro desenho do meandro divagante entre essas grandes escritoras. Na verdade, a escrita de Katherine provocou sustos contidos na dama da literatura inglesa moderna, poderosa em vários aspectos, sendo inclusive dona, juntamente com seu marido, Leonard Woolf, da Editora Howard, que publicou autores da grandeza de T. S. Eliot e de Sigmund Freud, de quem Virgínia foi amiga. A Howard também publicou Katherine Mansfield. Por meio desses encontros profissionais, elas se conheceram e tiveram conversas que, segundo os biógrafos de ambas, eram sempre mais ou menos tensas. Na verdade, a espontaneidade e, o caráter genuíno e ao mesmo tempo brilhante de Mansfield atingiram o orgulho e a frivolidade mental de Virgínia Woolf. Elas foram literalmente contemporâneas, tendo nascido na mesma década: Katherine Mansfield (1888-1923) e Virginia Woolf (18821941). Foram, em suas diferentes formas, as duas grandes intensidades humanas e literárias da Inglaterra das duas primeiras décadas do século XX. Apesar de não ter a infraestrutura do poder social e comercial, Katherine foi, a olhos vistos, ascendendo pela genialidade literária. Ambas mantiveram uma autêntica influência na literatura mundial.

A relação entre as duas foi complicada e às vezes tensa. No nosso modo de entender tratou-se de uma verdadeira relação de fascínio pelas similaridades de percepção entre as duas, o que implicou certa refração natural. Diferenças de fundo, gosto e modo de vida tornaram difícil, por vezes, encontrarem um terreno comum - e, claro, elas se tornaram rivais literárias. Ambas possuíam inteligência ardente, o olhar ferino para o que se poderia denominar de certo descaso para as coisas da vida. Porém, o que talvez tenha levado Virgínia Woolf a invejar Katherine Mansfield foi o tom do olhar e o descaso corajoso em relação aos valores mundanos e o modo como Katherine expressou isso, por meio de desvio artístico inigualável. Dentro de suas semelhanças, Katherine dava um passo adiante em certo modo de escrever que até hoje chega a incomodar. É como se marcasse um tom dissonante, se fosse música, que se encaixa

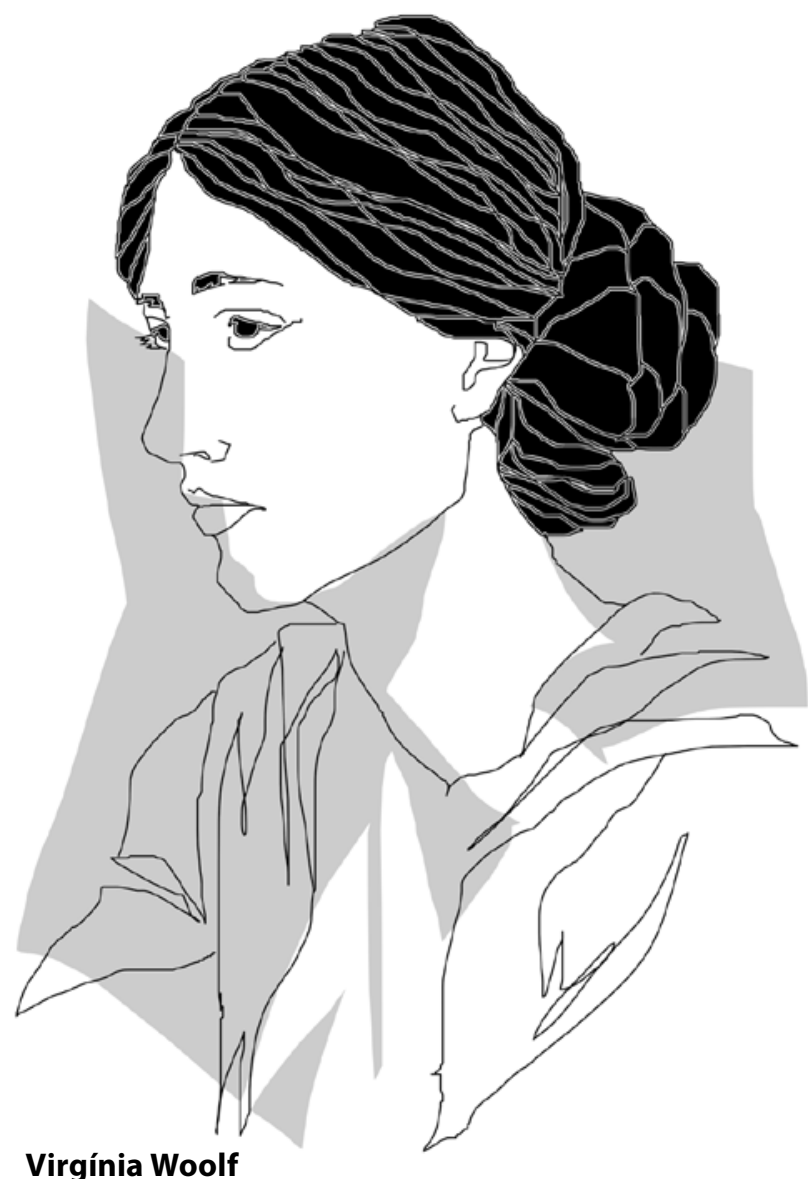

perfeitamente no verossímil crível da obra.

Mas a paixão de ambas pela escrita como um modo de vida levou-as a uma espécie de respeito mútuo e relutante. Elas se viram em espelho, a busca de si mesma se intensificou. Após a morte prematura de Mansfield, em 1923, Woolf disse: "Eu tenho um sentimento que eu penso nela, em intervalos durante toda a vida"; de fato, em 1931, confessou que "eu sonho com ela muitas vezes [...]". Como James King sugere em sua recente biografia: "A verdade é que Katherine Mansfield era a própria sombra de Virgínia Woolf”.

Virgínia Woolf foi a principal representante do grupo literário de Bloomsbury, centro de irradiação do modernismo britânico - era a mais afeita às experimentações da linguagem. Mansfield - em seu desenraizamento e independência - era mais visceral na sua relação com o mundo, com a vida vivida. Como já dissemos, apesar do brilho de ambas, parece-nos que essa visceralidade, aliada ao inventivo, deu certo, ou melhor, acabou por instaurar a diferença no estilo de Mansfield. O tom aristocrático de Woolf, suas marcas de classe que a definiram até no 


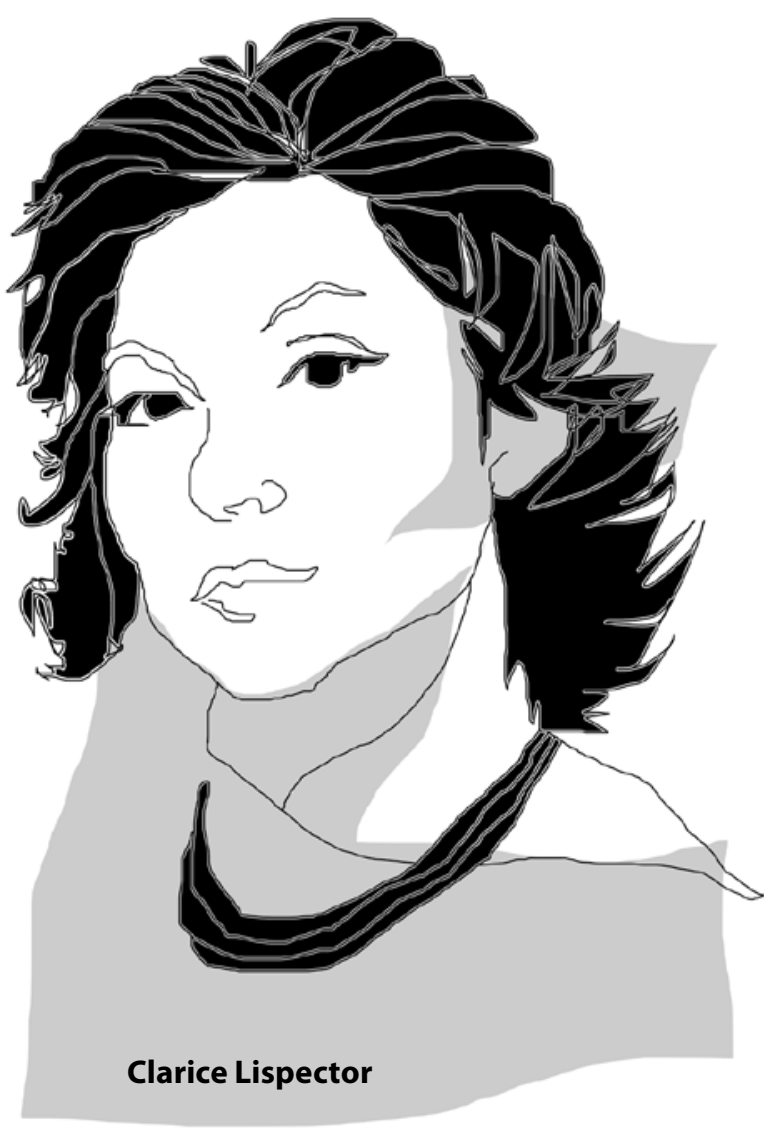

momento de seu suicídio, não foram superados. Ambas, atentas aos detalhes da existência prosaica e aos estados (ou paisagens) de alma de suas personagens, irônicas em relação às convenções sociais, voltadas para a sondagem crítica e criativa da própria condição feminina em um contexto ainda contaminado pelo puritanismo vitoriano. Uma buscou a morte aos 59 anos, ao encher os bolsos de pedra e se afogar no rio. A outra lutou, com uma vitalidade incisiva, contra a doença que a consumia aos poucos. A primeira deixou uma obra vasta, composta de nove romances, dezenas de contos, centenas de ensaios, algumas biografias, milhares de cartas e meio século de diários. A segunda deixou três livros completos de contos, dois inacabados, várias cartas e diários, não tendo podido, pelo escasso tempo de existência, dedicar-se ao romance, como queria. As duas tiveram vidas tumultuadas e sofridas, mas compartilhavam a mesma alegria no contato com bichos, flores, jardins e pomares.

Vai ser exatamente aqui, entre bichos, flores, jardins e pomares que o quarto elemento desse desenho maravilhoso vai ser completado. Depois de conviver com todos os movimentos que desenhei até aqui, percebi que fazia parte dessa linhagem a nossa esplêndida Clarice Lispector. Desculpe-me por alguns adjetivos, mas é a única forma de me aproximar, com todo o cuidado para não dilacerar a forma impermeável de seu universo, da palavra posta em questão de sopro dessa escritora. A questão da linhagem de Clarice se definiu logo após ter publicado o primeiro romance. Ela ficou incomodada quando o crítico Álvaro Lins a comparou a James Joyce e Virgínia Woolf, julgando que ela os tivesse adotado como modelos. Numa de suas cartas a Lúcio Cardoso, com quem se comunicou com muita frequência e intensidade, ela diz que só leu esses autores depois de ter escrito os primeiros livros. Na verdade, dentro de seu estilo singular e inigualável, a autora de A Paixão Segundo G. H., ou de O Lustre, ou de A Hora da Estrela revelou verdadeira obsessão pelo conjunto do ser de Katherine Mansfield. Mediante seu estilo muito particular e inconfundível, fica difícil detectar alguma influência. Entretanto, diferentemente de Virgínia Woolf, com atitudes de desdém inicial para revelar inveja após a morte da outra, a própria Clarice revelou, de maneira livre e desinteressada, seus sentimentos por Katherine. Na verdade, compreendo que, apesar das diferenças evidentes entre as duas, há uma proximidade muito grande de suas visões de mundo e de mundaneidade. Na expressão "visão de mundo" temos implícita uma série de coisas que não conseguimos nomear. Talvez fosse melhor dizer que do sincretismo entre os rudimentos da experiência e do espírito e as concepções do autor resulta um extrato a partir do qual realiza suas obras. Nesse sentido, as obras terão tons e matizes distintos, mas sairão da mesma categoria cromática, o que nos leva a vislumbrar o estilo de um autor manifestar-se em obras diferentes. E quando ocorre de uma obra desviar-se daquele estilo, surge a surpresa para todos, o estranhamento no processo de recepção. Para o leitor da obra de Clarice Lispector, ao se fazer alusão a um texto que ainda não tenha lido, antes de tudo 
vem um tom, um maneio de elocução, até mesmo uma profunda e cortante concepção de humano e de vida. Ao se dizer "gosto de Clarice Lispector", essa afirmação traz todo um universo que envolve estilo e concepção. O que será que terá movido esse leitor a fazer essa asserção genérica? Podemos inferir como ele vê a relação entre Água Viva (1973) e Um Sopro de Vida (Pulsações), mas se torna menos plausível, por exemplo, inferirmos relações entre Água Viva (1973) e A Hora da Estrela (1977). Entretanto, existem elementos quase inexplicáveis, à primeira vista, que as aproximam. Esses elementos não são, evidentemente, de fábula ou de tema. São "fibras" estilísticas compostas a partir do mesmo extrato. No caso específico de Clarice Lispector, torna-se difuso o que denominamos de "mundo do autor". Se tirássemos as datas de sua primeira produção (Perto do Coração Selvagem) e de sua última (A Hora da Estrela) e as lêssemos naturalmente, sentiríamos suas diferenças, mas em ambas notaríamos intensidades similares. Trinta e quatro anos separam as duas obras (1943-77) mas o extrato é o mesmo, por mais que se tenha ampliado a gama de ingredientes para sua produção. Nessa atmosfera que denominamos "mundo do autor", formam-se verdadeiras teias de influências de toda ordem e categoria. As relações são plurais e nem sempre evidenciadas. As afinidades entre autores de gerações próximas e as rivalidades entre autores da mesma geração acabam gerando muitas vezes efeitos especiais e duradouros até em gerações futuras. Em certos casos dessas "afinidades", podemos entender como "meandros divagantes" que se revelam nas obras dos autores.

Apesar de total independência de estilo, não se pode negar as marcas de Katherine Mansfield em Clarice Lispector. Correspondem a uma afinidade profunda, tanto estilística como psicológica e moral. Haurida no momento em que ela descobria em si mesma o dom da criação e a capacidade de lidar com um mundo imaginário, não marcou apenas seu instante inicial de escritora, como a acompanhou a vida inteira. Em ambas há uma espécie de identidade do olhar: um olhar deslumbrado e pronto para enxergar as coisas miúdas ou quase imperceptíveis, a subterrânea fervilhação da vida cotidiana, e captar o segredo das paisagens e o mistério engasgado nas criaturas aparentemente banais - um olhar de quem está vendo as coisas pela primeira vez e consigna essa descoberta num estilo poético partilhado entre a concretude e a evanescência. Na biblioteca de Clarice Lispector figurava Felicidade, o Bliss de Katherine Mansfield traduzido por Érico Veríssimo, com sinais de assídua leitura. Em Nápoles, em 1944, ela manifestou a Lúcio Cardoso, numa carta, o seu encantamento diante de uma seleção da correspondência de Katherine Mansfield traduzida para o italiano. Nas Correspondências de Clarice, sobretudo a Lúcio Cardoso, são os momentos mais dóceis e intimistas da escritora em que expõe seus gostos e seus tédios e seus modos tão peculiares de ser. Nessas cartas, a escritora revela suas descobertas, suas leituras, suas opiniões sobre a recepção crítica de sua obra, enfim, pode-se ter de perto os claros sentimentos dela em relação ao seu universo de invenção e de sentimentos do cotidiano. Numa dessas cartas para Lúcio, escrita da África, que devemos assinalar como uma das mais interessantes, ao falar de suas leituras, assim se manifesta: "Reli a Porta Estreita de Gide, sobretudo encontrei as Cartas de K. Mansfield. Não pode haver uma vida maior que a dela, e eu não sei o que fazer simplesmente. Que coisa absolutamente extraordinária que ela é".

É certo que Clarice Lispector parecia ter sempre, desde a infância, uma natural propensão para a leitura da grande literatura, e suas cartas revelam que se alimentava permanentemente da leitura ou da escrita. Da mesma forma que olhava para o mundo e flagrava com intensidade e obsessão coisas e pessoas e bichos e plantas e deles extraía o elixir do mundo, da mesma forma transformava em matéria metamorfoseada as obras que lia:

"No dia em que eu conseguir uma forma tão pobre quanto eu sou por dentro, em vez de 
carta, parece que já lhe disse, você recebe uma caixinha cheia de pó de Clarice. Talvez você ache o título mansfieldiano porque você sabe que eu li ultimamente as cartas de Katherine. Mas acho que não. Para as mesmas palavras dá-se essa ou aquela cor. Se eu estivesse lendo então Proust alguém pensaria num lustre proustiano (meu Deus, ia escrevendo proustituto!) [...]”.

Uma passagem aparentemente desinteressada traz um conteúdo de extrema riqueza para a compreensão seja da relação de Clarice com a escritora Katherine Mansfield seja sobre seu modo de buscar a forma da substância de seu ser. Não nega certo flerte com o extrato de Katherine, mas salvaguarda antes de tudo a sua relação com a palavra e com o estilo que lhe impõe. Poder-se-ia dizer que a relação entre Clarice Lispector e as duas escritoras em língua inglesa é efetiva mas sutilíssima e perspicaz. Há que se observar a evidente diferença da relação entre Clarice Lispector e Katherine Mansfield e a relação entre Virgínia Woolf e Katherine Mansfield. No primeiro caso sentimos uma certa iluminação no modo como a escritora brasileira vê a escritora nascida na Nova Zelândia. No estilo, sentimos em Clarice a presença do êxtase exaltado por Katherine, principalmente em Bliss, em toda a sua obra. Diríamos que isso já estava nos seus romances desde o princípio. Não se diria, portanto, de influência, mas de convergência de espírito das duas escritoras. Entretanto, o modo como essa sensação de êxtase se manifesta nas obras de Clarice é o que determina a genialidade da escritora. É como se suas personagens estivessem permanentemente em estado de êxtase bem como as atmosferas criadas. E esse estado permanece quase sempre contido e ao mesmo tempo prestes a manifestar-se, sobretudo nos contos, devido ao seu estado de síntese e de tensão no modo de compor cada palavra, para não dizer cada traço de suprassegmento na construção da dicção da linguagem.

No caso de Virgínia Woolf, a relação com Katherine ocorreu de outra forma e em cir- cunstâncias distintas. Há que se considerar o temperamento complexo da escritora inglesa e sobretudo suas idiossincrasias. De repente se viu diante de um ser com o perfil diferenciado, irreverente e ao mesmo tempo brilhante naquele ponto que ela mais prezava: no estilo. A forte sensação de presença de Katherine em sua vida tornou-se uma espécie de obsessão: "Tenho o pressentimento de que vou pensar nela, em intervalos, durante toda a minha vida". E, de fato, quase dez anos depois de sua morte, confessou que sonhava muito com Mansfield, com quem mantivera um relacionamento tenso, marcado por uma certa rivalidade literária e várias afinidades intelectuais. As similaridades de percepção diante do cotidiano são inquestionáveis, entretanto, o modo de expressar essa percepção parece ter atingido de maneira pontiaguda a escritora inglesa. Além de estarem inseridas nas novas técnicas modernistas de escritura, tais como a subversão aos modos realistas de narrar, como outros escritores do início do século, elas inventaram uma poética narrativa que desse conta de meandros divagantes da alma de suas personagens por meio do "monólogo interior" ou do "fluxo da consciência", criando universos ficcionais densos e instigantes, de grande impacto sensorial. Cada uma com sua dicção particular e suas diferenças no modo de lidar com a realidade, a linguagem e a experiência cotidiana. Aqui e acolá, o leitor atento percebe as marcas do estilo de Mansfield em alguns contos de Virgínia Woolf, sobretudo aqueles da década de 20, como é o caso de "Happiness", em que a questão do êxtase é trabalhada de maneira muito similar à forma presente em "Bliss". O efeito conseguido no conto de Virgínia deixa bastante a desejar. Entretanto, existem muitos pontos convergentes nas duas escritoras. Como assinala Maria Esther Maciel, poeta, ensaísta e professora de Literatura da Universidade Federal de Minas Gerais,

"Como Woolf, Mansfield aposta na força da ambiguidade e da polissemia, optando por uma linguagem de explícita visualidade. Vale ressaltar, inclusive, o caráter quase 
cinematográfico de vários contos da coletânea, como aqueles que descrevem cenas e situações flagradas do interior de um trem em movimento. São verdadeiros travellings, em modulações cromáticas que imprimem na própria superfície da escrita as cargas de complexidade do olhar da 'câmera', como se pode atestar sobretudo no instigante 'A Pequena Governanta', que narra a história de uma moça que viaja para a Alemanha, para assumir o emprego de governanta em uma casa de família, vivendo uma insólita experiência de viagem. $\mathrm{O}$ vigor imagético se explicita também no último conto, 'A Mosca', que traz o embate desesperado pela vida (seria uma alegoria da própria contenda da autora contra a morte?) de uma mosca dentro de um tinteiro e que, depois de salva, ainda tem que lutar contra o jogo sádico do chefe do escritório, que nela joga sucessivas gotas de tinta, só para avaliar a resistência do inseto, que acaba perecendo".

Ainda acrescenta a ensaísta:

"As duas obras vêm, assim, abrir para o leitor brasileiro um universo feminino de intimidades lúcidas e paisagens raras, extraídas da realidade prosaica das coisas vividas ou lembradas. Embora, nesse caso, as lembranças se explicitem também como quase improvisos, como pedaços da imaginação. Isso porque, em Woolf e Mansfield, como diria Clarice Lispector (escritora que integra essa mesma linhagem), 'escrever' é tantas vezes lembrar-se do que nunca existiu".

A impossibilidade de separar a carne da pele. Esse fenômeno ocorre no procedimento ou antiprocedimento inventivo de Katherine Mansfield. Como se pôde ler na sua biografia, tornamo-nos incapazes de armar quaisquer comentários críticos acerca de suas atitudes de vida. Elas foram realizadas e pronto. Essa é a verdade. Quando se tinha a impressão de que nada mais poderia acontecer, ela surpreendia, às vezes a si mesma. Um ser como esse deixa o mundo estarrecido e mal percebe o que provocou. São pessoas (raras pessoas) que deixam muito claro que são donas de suas vidas e que somente a elas dizem respeito as consequências. Atualmente temos acesso ao conjunto de sua obra, inclusive às suas cartas (que tanto impressionaram Clarice), e isso confere mais condições para os estudos críticos. Interessante que, contrariando meus princípios críticos antibiográficos, no caso especial da autora de Bliss, ocorre (ao menos em mim isso ocorre) o desejo de conhecer a pessoa de Katherine. Algumas vezes me pego olhando para suas fotos, para a expressão de seu rosto, sua boca de finos lábios, seu estranho modo de se pentear, como se mantivesse eternamente seus 14 anos, e seus olhos. Seus olhos atuam como a fonte para aquele universo travesso e maravilhoso em que o mistério entra como se não quisesse nada. Sua narrativa flui como água que escorre pela vidraça e que vai lentamente inundando tudo até atingir o alicerce. Dentre as maravilhas assustadoras que sua narrativa constrói, destacam-se os vácuos semânticos. Talvez estejam nesse efeito estético as marcas de competência de estilo que os demais escritores contemporâneos e posteriores a ela não conseguiram imitar e que os incomodaram tanto: as relações com as pequenas coisas da vida e ao mesmo tempo ver nessas coisas as transmutações possíveis para o campo do imaginário. A impossibilidade de cercear as coisas do espírito que embasam a criação. A transformação das referências em signos e o retalhamento desses signos em processo de bricolagem.

Se eu pudesse provocar num instantâneo reações alquímicas no tempo e no espaço e metamorfosear a ordem do tempo, provocaria um encontro, para o chá das cinco, dessas quatro mulheres adoráveis e, evidentemente, ardentes de espírito. Não ousaria estabelecer uma comparação entre elas, mas daria a vida para ver quanto tempo elas se suportariam em equilíbrio aparente. Se isso fosse possível, abrir-se-ia a oportunidade para que o movimento se completasse, isto é, que Katherine Mansfield e Virgínia Woolf fossem leitoras das brasileiras Clarice Lispector e Ana Cristina César. 